\title{
Pinguicula in the Lower 48: Habitat Notes
}

BARRY A. RICE $\bullet$ Center for Plant Diversity $\bullet$ University of California $\bullet$ One Shields Avenue $\bullet$ Davis

- California 95616•USA・brice@sierracollege.edu

The "Lower 48" refers to the 48 contiguous states of the USA (i.e., excluding only Hawai'i and Alaska, but including Washington, D.C.). Within this region, there are eight species of Pinguicula, mostly confined to the southeastern part of the country. Since the ranges of southeastern species overlap so much, it is usually the case that the carnivorous plant botanist exploring wetland habitats is likely to encounter more than one species. Even so, the various species have subtle differences in habitat preferences.

What follows are some of my observations on general preferences. However, if you go exploring yourself, don't be surprised if plants break the rules...perhaps they haven't read my notes. And after all, one of the fun things about observing organisms in the wild, is learning how they often innovate in surprising ways!

Let's play a bizarre little thought experiment. Suppose you were descending a low hill, towards a wetland in the low country of the southeastern USA. In what order might you expect to encounter Pinguicula species?

\section{Upland species}

Long before you reach areas of open water, the first species you would be likely to encounter would be Pinguicula pumila - this species often enjoys sandy areas that are surprisingly dry. In

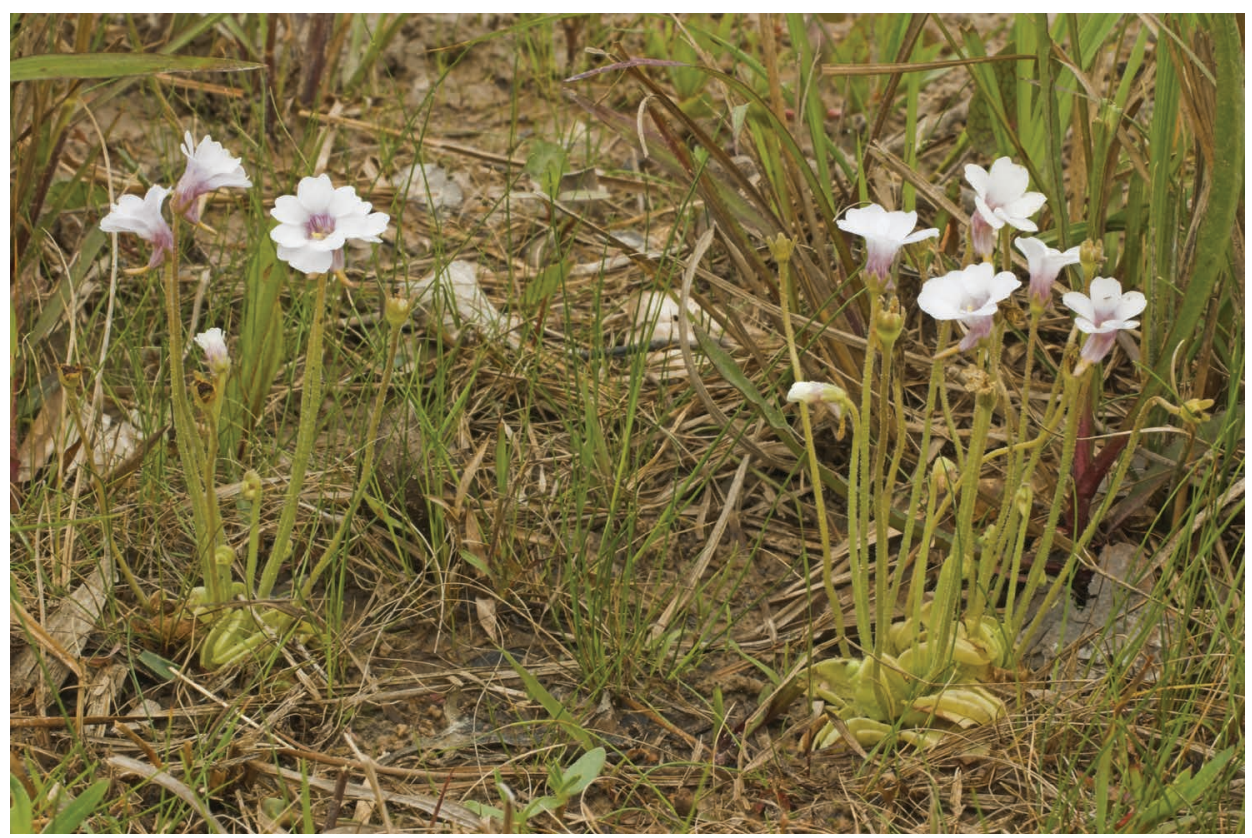

Figure 1: Pinguicula pumila in Tyler County, Texas. 
some situations, the habitats may be suitable only for a portion of the year - that's ok, because the plant is perfectly happy functioning as a short-lived annual in such situations.

I find Pinguicula pumila truly fascinating. In parts of Florida, especially southwards towards the Keys, the plants tend to have very small, crumpled looking flowers that may be white, purplish, or yellow - in the latter case, such plants have been given the name P. pumila var. buswellii. Meanwhile, in parts of Texas I've seen much larger plants with commensurately large flowers that reminded me of Pinguicula agnata (Fig. 1). This variation is fascinating - are we seeing speciation at work? If humans hadn't come along, might there have been new species on the evolutionary horizon?

Dropping a few crucial centimeters in elevation, the ground becomes almost imperceptibly moister. In these locations you can start picking up Pinguicula lutea and P. caerulea (Fig. 2).

I'm talking broad strokes here. There's so much variation from site to site that the three speciesP. caerulea, P. lutea, and P. pumila — are probably just best treated as a habitat trio.

While we are on our fictional wetland trip, make sure you take time to enjoy the variation in flowers. Pinguicula caerulea can vary from pure white flowers (=P. caerulea f. leucantha, Fig. 7) to lightly veined flowers, to lilac-blushed flowers, to nearly pure violet flowers. Analogously, $P$. lutea can range from white-flowered forms ( $P$. lutea f. alba, Fig. 7), to creamy flowers, to deep yellow. The petals of $P$. lutea are particularly variable, and can range from being barely notched at the tip, to multiply divided distally into fingerlike projections (Fig. 7). Weird.
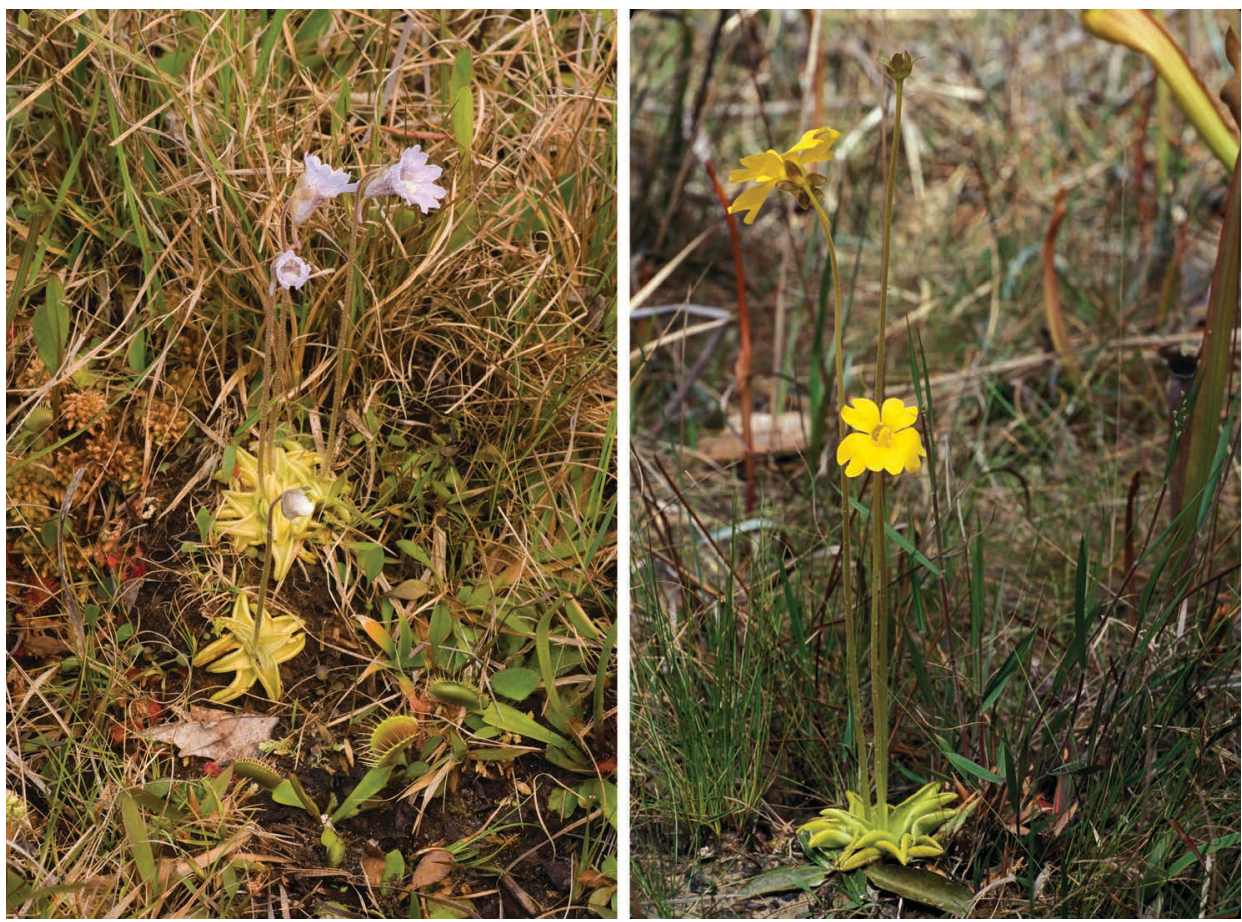

Figure 2: Left, Pinguicula caerulea in Onslow County, North Carolina. Right, Pinguicula lutea in Stone County, Mississippi. 
If you've managed to keep your feet dry up to now, things are going to change rapidly. Dropping down a few more centimeters means we'll be in soft mucky mud, and then-dropping further-entering standing water.

Sloshing around in reedy, grassy water, especially near the edges of trees, you have a chance to encounter Pinguicula ionantha. (Tread carefully, as it is Federally listed as being "Threatened.") Pinguicula ionantha lives in this extremely delicate substrate, with its roots and lower parts in fully saturated muck (Fig. 3). Always keep an eye on flower color when enjoying $P$. ionantha - while usually creamy white, some plants can be flushed with various amounts of lilac (Fig. 7). You are likely to see little monitoring tags on the plants because their populations are closely monitored by agency botanists!

In comparably wet conditions, you're likely to encounter Pinguicula planifolia. This very large species often enjoys open mud flats in the bottom of seasonally filled ponds (Fig. 4). When the

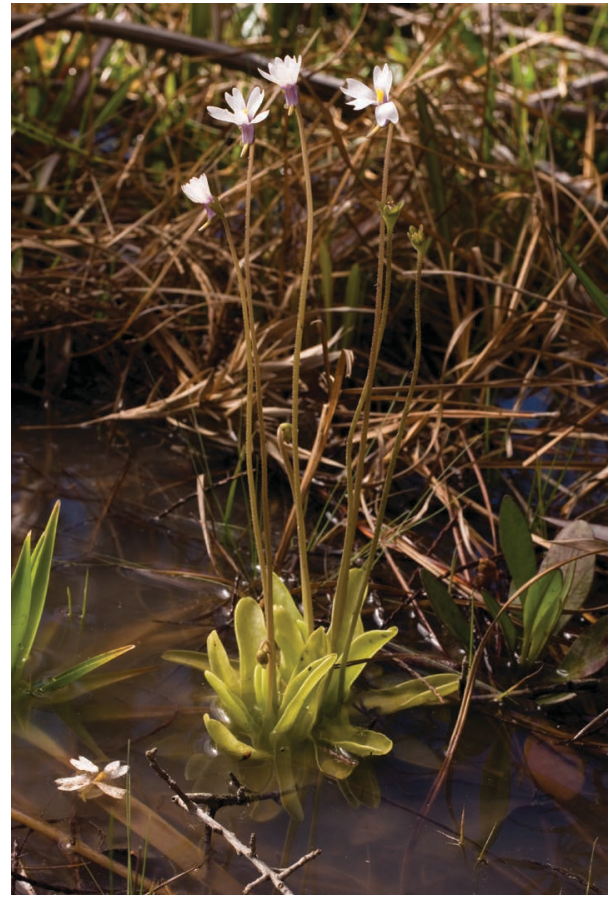

Figure 3: Pinguicula ionantha in Liberty County, Florida

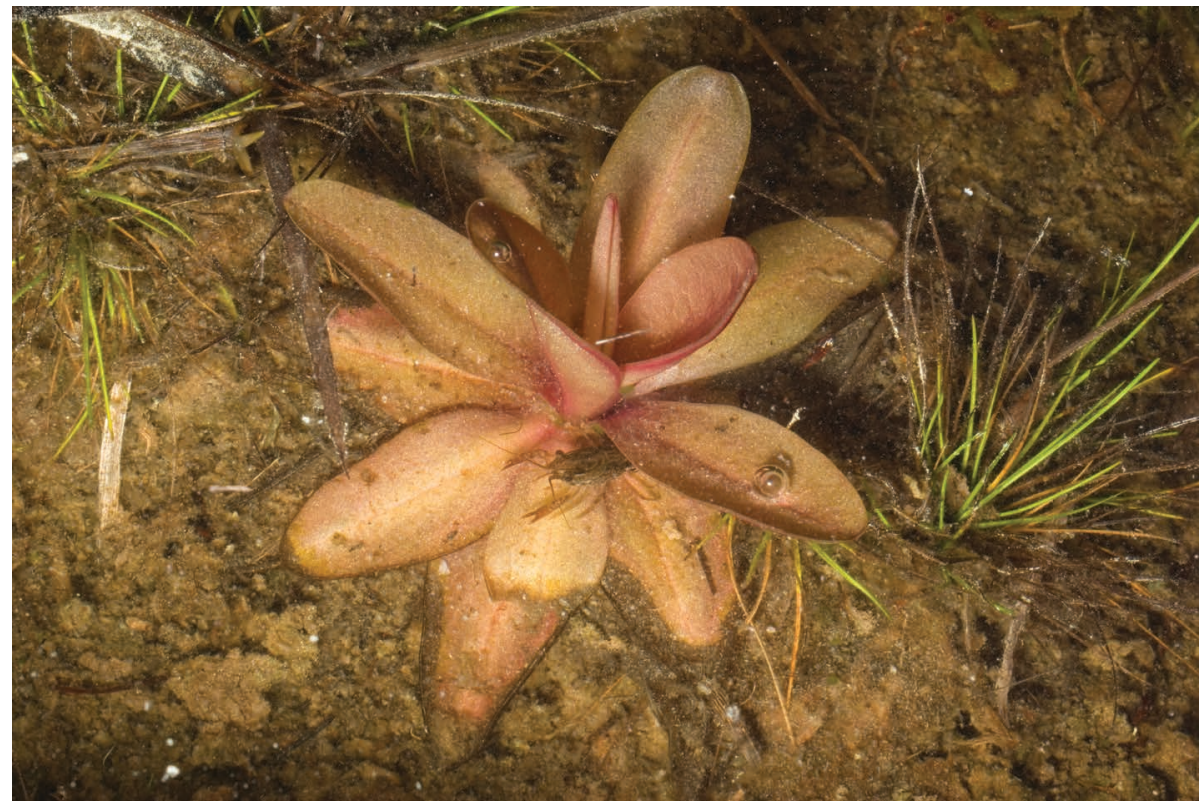

Figure 4: A crawfish seeking cover under a submerged Pinguicula planifolia in Liberty County, Florida. 


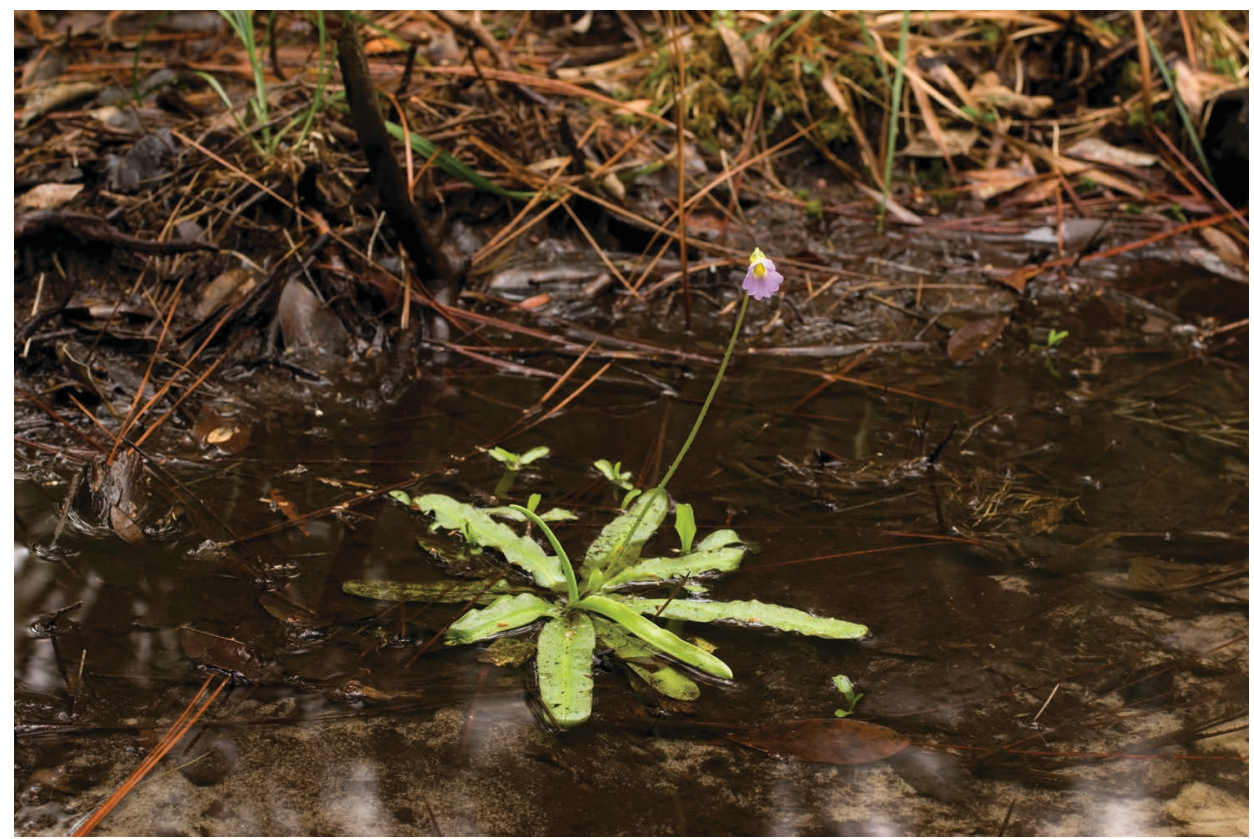

Figure 5: A free-floating Pinguicula primuliflora in Walton County, Florida.

water is low, they're fully exposed on open mudflats, but during wetter times they can be in water ankle deep, or even deeper! This species is regularly pale lilac (Fig. 7), but oddly often produces flowers with abnormal numbers of petals. I've seen them with anywhere between three and nine!

Our last species to be encountered in this trip, Pinguicula primuliflora, also loves wet, inundated situations. However, instead of being submerged in deep water, P. primuliflora might be found floating on the water's surface - usually part of a vegetation mat — but occasionally floating freely on the water's surface (Fig. 5). Interestingly, P. primuliflora is not restricted to still water-I've seen it in riparian habitats, floating in relatively quiet, protected corners of small streams. This very charismatic species has flowers that usually have bicolored flowers - pink distally, white proximally. It is also the species most likely to bud plantlets from its leaves.

Hibernaculum-forming plants

Moving to other parts of the USA, we encounter two more species-Pinguicula macroceras and $P$. vulgaris. These are very similar plants - indeed they are so similar that plants in cultivation can be hard to identify confidently. In the wild, range is the easiest way to tell them apart. Pinguicula vulgaris is found in flat, quiet wetlands in the northeast and Great Lakes region. In terms of wetness, it prefers the same moistness as the Pinguicula ionantha-planifolia-primulifiora group. Meanwhile, Pinguicula macroceras is found in the Pacific states, and is usually found in wet seepages and cliffs (Figs. 6, 7).

The Pinguicula of the Lower 48 comprise a lovely group of plants. I encourage you to seek them out and make your own habitat observations. While many of your observations will probably support my general outline above, no doubt you'll find exceptions to them as well - that is just one of the many fascinating aspects of these remarkable plants. 


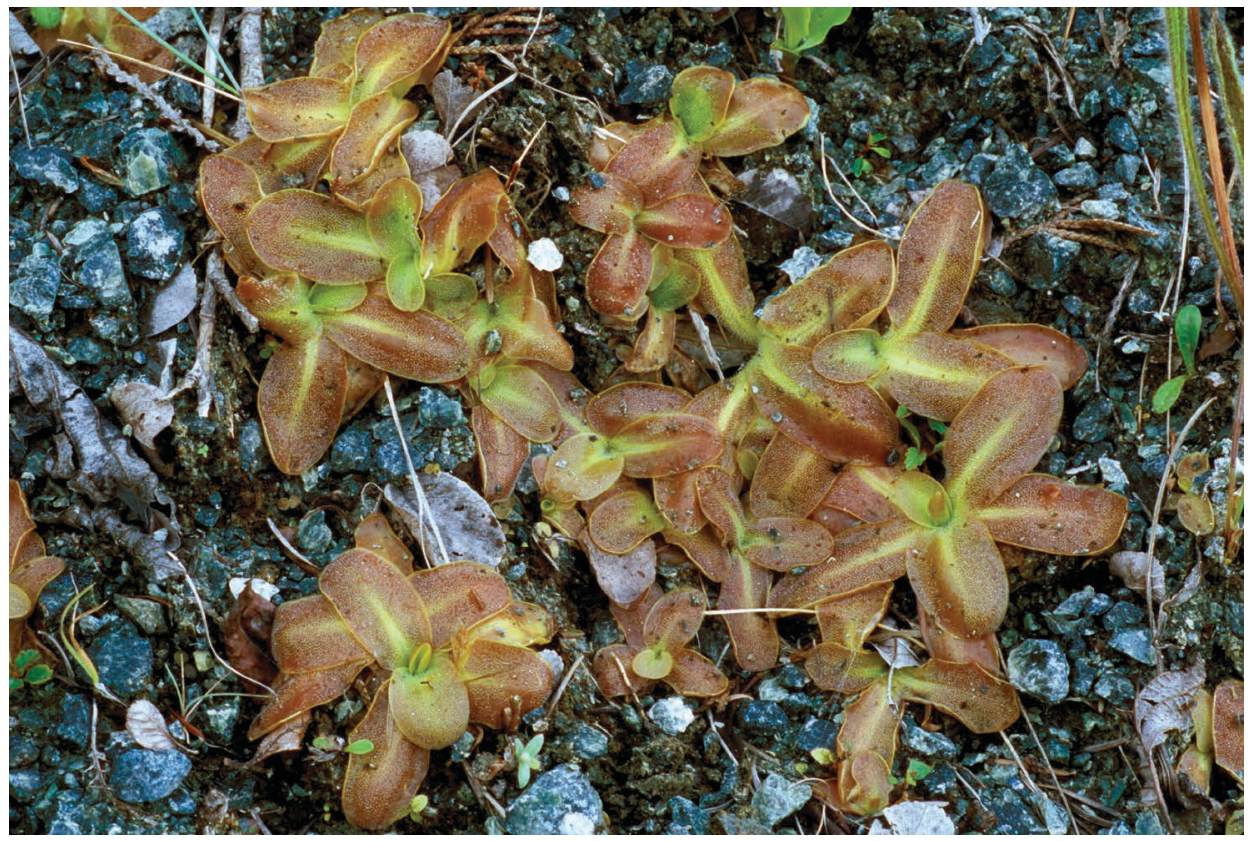

Figure 6: Red-tinged Pinguicula macroceras in Del Norte County, California.

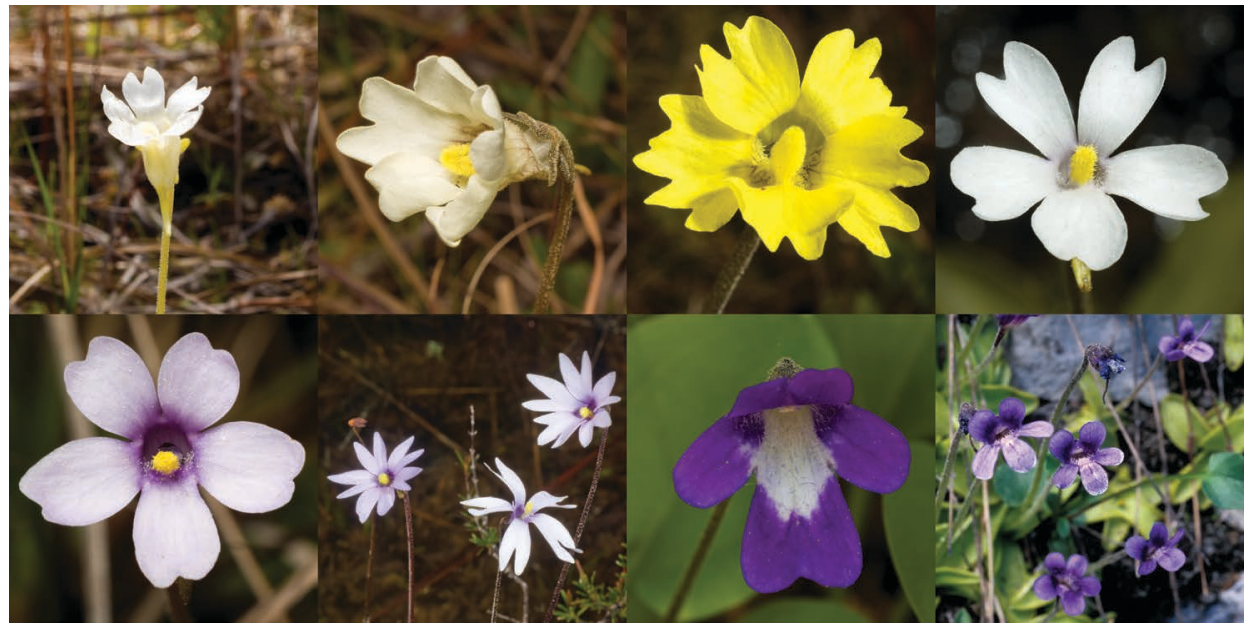

Figure 7: Variation in Pinguicula flowers. Top row, left to right: $P$. caerulea f. leucantha, Onslow County, North Carolina; P. Iutea f. alba, Liberty County, Florida; P. Iutea with strong petal lobation, Liberty County, Florida; P. ionantha with white flowers, Liberty County, Florida. Bottom row, left to right: P. ionantha with purplish flowers, Liberty County, Florida; P. planifolia floral variation, Liberty County, Florida; P. macroceras with large white floral spot, Siskiyou County, California; P. macroceras with almost absent white floral spot, Wallowa County, Oregon. 